Научная статья

УДК 3.304 .4

DOI: $10.17213 / 2075-2067-2021-6-275-285$

\title{
ЭКОЛОГИЧЕСКИЕ АСПЕКТЫ РОССИЙСКОЙ УРБАНИЗАЦИИ/ДЕУРБАНИЗАЦИИ
}

\author{
Людмила Львовна Штофер ${ }^{\natural}$, Ольга Михайловна Шевченко \\ ${ }^{1}$ Ростовский государственный экономический университет (РИНХ), \\ Ростов-на-Дону, Россия \\ ${ }^{2}$ Южный федеральный университет, Ростов-на-Дону, Россия \\ ${ }^{1}$ Filosofiya327@yandex.ru ${ }^{\bowtie}$, ORCID: 0000-0003-0205-7468, AuthorID РИНЦ: 928937 \\ 2olgashv2007@yandex.ru, ORCID: 0000-0001-6726-7269, AuthorID РИНЦ: 479776
}

Аннотация. Цель исследования заключается в рассмотрении экологических аспектов прочессов урбанизации/деурбанизачии в России.

Методологической основой исследования являются сочиокультурный подход к пониманию становления городской организащии общественной жизни; теории урбанизаџии, позволяющчие исследовать факторы и специифику функциионирования города как экосоииального пространства.

Результаты исследования. Экологические аспекты российской урбанизаиии/деурбанизации отражают как глобальные тенденции развития человечества, так и иивилизачионные особенности России. Последние связаны с быстрым разрушением природоориентированного сознания традиционного общества и укоренением идей покорения и эксплуатации природы; с догоняющим характером советской модернизации, потребовавщей за короткий период осуществить урбанизаџию/индустриализацию аграрной страны; с дисбалансом между новачиями (стремительным ростом городов) и традииионализмом (аграрной ментальностью и общинным типом сознания их населения); с тенденциями деурбанизации, возникшими в постсоветский период и связанными с деиндустриализачией, следствием которой стало массовое появление депрессивных территорий; с наличием значительной территории, позволяющей пока не сильно озадачиваться последствиями неэффективных программ утилизации промышленных и бытовых отходов.

Перспективы исследования. Работа открывает перспективы для дальнейшего исследования экологических угроз российских процессов урбанизачии/деурбанизации.

Ключевые слова: урбанизачия, деурбанизачия, город, экосочиальное пространство, мегаполизация, моногород, антропоцентристско-сциентистская парадигма

Для цитирования: Штофер Л. Л., Шевченко О. М. Экологические аспекты российской урбанизации/деурбанизации // Вестник Южно-Российского государственного технического университета. Серия: Социально-экономические науки. 2021. T. 14, № 6. C. 275-285. http:// dx.doi.org/10.17213/2075-2067-2021-6-275-285.

(С Штофер Л. Л., Шевченко О.М., 2021 
Original article

\title{
ENVIRONMENTAL ASPECTS OF RUSSIAN URBANIZATION/DEURBANIZATION
}

\author{
Lyudmila L. Shtofer ${ }^{1 凶}$, Olga M. Shevchenko ${ }^{2}$ \\ ${ }^{1}$ Rostov State University of Economics (RSUE), Rostov-on-Don, Russia \\ ${ }^{2}$ Southern Federal University, Rostov-on-Don, Russia \\ ${ }^{1}$ Filosofiya327@yandex.ru ${ }^{\bowtie}$,ORCID: 0000-0003-0205-7468, AuthorID RSCI: 928937 \\ 2olgashv2007@yandex.ru, ORCID: 0000-0001-6726-7269, AuthorID RSCI: 479776
}

\begin{abstract}
The purpose of the study is to examine the environmental aspects of urbanization/ deurbanization processes in Russia.

The methodological basis of the study is sociocultural approaches to understanding the formation of the urban organization of public life; theories of urbanization, allowing to study the factors and specifics of the functioning of the city as an ecosocial space.

Research results. The environmental aspects of Russian urbanization/deurbanization reflect both global trends in human development and the civilizational features of Russia. The latter are associated with the rapid destruction of the nature-oriented consciousness of traditional society and the rooting of ideas for the conquest and exploitation of nature; with the catching-up nature of Soviet modernization, which required the urbanization/industrialization of an agrarian country in a short period; with an imbalance between innovations (rapid growth of cities) and traditionalism (agrarian mentality and the communal type of consciousness of their population); with the tendencies of deurbanization that arose in the post-Soviet period and associated with de-industrialization, which resulted in the massive emergence of depressed territories; with the presence of a large territory, allowing for the time being not to be very puzzled by the consequences of ineffective programs for the utilization of industrial and domestic waste.

Research prospects. The work opens up prospects for further research of environmental threats to Russian urbanization/deurbanization processes.

Keywords: urbanization, deurbanization, city, ecosocial space, megapolization, singleindustry town, anthropocentric-scientistic paradigm

For citation: Shtofer L.L., Shevchenko O.M. Environmental aspects of Russian urbanization/ deurbanization // Bulletin of the South Russian State Technical University. Series: Socio-economic Sciences. 2021; 14(6): 275-285. (In Russ.). http://dx.doi.org/10.17213/2075-2067-2021-6-275-285.
\end{abstract}

Введение. Любые проблемы, связанные с Россией, принято рассматривать через призму исторически сложившихся специфических черт в их постановке и решении. Однако прежде чем обратиться к цивилизационным особенностям российской урбанизации/деурбанизации и ее экологическим аспектам, необходимо определиться с трендом мирового развития.

Человеческая популяция уникальна тем, что в отличие от других видов, имеющих ограниченные ареалы проживания, она сумела расселиться по всему миру и создала в разных регионах идентичные способы организации социальной жизни, связанные, в частности, с устойчивыми формами совместного проживания.

Развитие человеческой цивилизации прошло несколько этапов, которые не только коррелируют с социальной типологизацией (традиционное, индустриальное, постиндустриальное), но и могут быть рассмотрены через призму отношений «человек природа». Человеческая «растворенность» 
в природе, на первом этапе сопровождающаяся бродячим образом жизни, уже на втором сменяется оседлым, деревенским образом жизни и появлением соответствующего ему вида производственной деятельности - сельского хозяйства. Наконец на третьем этапе организация форм совместного проживания достигает своей высшей точки, результатом чего становится появление альтернативного деревенскому городского образа жизни и разнообразных видов производственной деятельности. Именно город закладывал основы стандартов потребления своего времени, а также представление о комфорте и безопасности жизни.

Исторически любое сельское поселение всегда было интегрировано в природу, в то время как город был отделен от нее и, по сути, противостоял ей. Сельское поселение не имело четко очерченной границы, плавно «перетекая» от зоны проживания населения к сельхозугодьям, а затем и к естественно-природному ландшафту. Искусственность городской среды и ее отделенность от природы исторически подчеркивалась демаркационной линией в виде впечатляющих рукотворных укреплений. Как результат города противостояли природной среде во всех отношениях: от образа жизни населения, осуществляемых им видов деятельности до визуального образа - выделенного из окружающей среды искусственного доминантного пространства. Именно городской образ жизни с течением времени возобладал в разных регионах мира, став трендом цивилизационного развития человечества.

Методология и методы исследования. В статье использован социокультурный подход, разрабатываемый в трудах Ф. Броделя, М. Вебера, Ж. Ле Гоффа, который позволяет понять эволюцию городской формы жизни, ее экономические и культурные особенности [5; 6; 14]. Концептуальными для исследования выступают современные теории урбанизации, представленные в работах зарубежных ученых [15;23] и российских исследователей $[7 ; 13 ; 20]$.

Различные аспекты экологических рисков урбанизации исследуются в работах А.Б. Агафоновой, Л.Н. Блинова, И. Л. Перфиловой, Л.В. Юмашевой и др. [1; 3]. Дан- ные подходы являются теоретико-методологической основой исследования специфики процессов российской урбанизации/деурбанизации и их влияния на экологию городов.

\section{Урбанизации как тренд мирового раз-} вития. В настоящее время исследование города и городского образа жизни все чаще связано с экологическими проблемами, прежде всего влиянием урбанизации на городскую и окологородскую экосистемы, а также биосферу в целом. Город начинает рассматриваться как экосоциальное пространство, в котором природа и результаты человеческой деятельности оказываются нерасторжимо и подчас трагично взаимосвязаны.

Философия, всегда откликавшаяся на наиболее острые вопросы времени, начала глубоко осмысливать проблему отношений между человеком и природой только в Новое время, когда резко возросли темпы и масштабы урбанизации, а вместе с ними и негативное влияние на экологию. Уже в этот период ценность искусственного и естественного начинает оцениваться по-разному. Ш. Монтескье приветствует создание искусственной (городской) среды обитания, видя в ней апофеоз развития цивилизации [16]. Его оппонент Ж.Ж. Руссо, напротив, воспевает первозданную природу, видя в городе лишь механистичность и бездуховность [20].

Современный мир не оставляет сомнений относительно того, чьи идеи возобладали в общественном сознании, отразив общее стремление человеческой цивилизации к искусственным (городским) формам существования и искусственным (технико-технологическим) средствам решения возникающих задач. Подтверждением этого стала мегаполизация как этап урбанизационного развития, а вместе с ней увеличение и возрастающая неравномерность нагрузок на естественноприродную среду, остающуюся по-прежнему основной ресурсной базой.

Несмотря на то, что подавляющее большинство населения планеты уже в древности избрало оседлый образ жизни, количество городов, тем более имеющих значительную численность населения, было относительно невелико, а специфика городского образа жизни, предполагающая доминирование определенных - ремесленных и торговых - 
видов деятельности, только начинала формироваться. Неравномерность урбанизациионного процесса в глобальном масштабе приводила к тому, что место лидера в древности и в средневековье попеременно делили Восток и Запад. Традиционные общества преимущественно занимались сельским хозяйством и в силу экстенсивного характера производственной деятельности не могли нанести существенного урона даже региональной экологии, не говоря о биосфере планеты в целом.

Ситуацию поддерживала мифологическая картина мира, рассматривающая природное и социальное как единое целое. Начавшее складываться религиозное мировоззрение, выделив человека и подчеркнув его значимость, не позиционировало последнего как полновластного хозяина планеты, поскольку не только создателем, но и верховным управителем всего являлся Бог.

Подобные мировоззренческие установки приходят в противоречие с потребностями общественной жизни в тот момент, когда человек, стремясь качественно изменить образ жизни, включая деятельностные аспекты, начинает углубляться в природу. В Новое время Запад закладывает основу антропоцентристско-сциентистской ценностно-мировоззренческой парадигмы и, опираясь на науку, открывает возможность промышленных методов производства продукции. Совокупность этих факторов определяет параметры индустриального общества, порождая, по мнению исследователей, стремительный демографический рост и массовый исход населения западных стран из сельской местности в города [7]. Так, в Новое время вопрос о тренде цивилизационного развития окончательно решается в пользу урбанизации, а место лидера переходит к Западу.

В этот же период впервые отчетливо обозначаются экологические проблемы, связанные с городом как местом значительной концентрации людей и промышленных производств, - существенное загрязнение почвы, воды и воздуха городской и прилежащей к нему территории.

Генезис российской урбанизации. Генезис российской урбанизации восходит к эпохе Киевской Руси, когда Русь начина- ют называть Гардарикой - страной тысячи городов. Данный период непродолжителен и сменяется замедлением темпов урбанистического развития, порожденных феодальной раздробленностью и монголо-татарским игом. Возвышение Москвы и создание централизованного русского государства влияет на темпы урбанизации, но незначительно. Городов, особенно крупных, немного. Торговые контакты, стимулирующие рост городского населения и развитие производственной деятельности, практически полностью связаны с внутренним рынком, а предметом ограниченного экспорта является, прежде всего, сельскохозяйственная продукция. Ситуацию усугубляет крепостное право. Оно не позволяет интенсифицировать внутреннюю миграцию, обеспечив прирост городского населения за счет населения сельского, ограничивает деловую активность большей части населения, не позволяет создать рынок труда, необходимый для капиталистического производства. Наконец, господствующий тип мировоззрения - религиозный — препятствует формированию гуманистических, индивидуалистических ориентаций и развитию позитивного знания, детерминирующего промышленный подъем.

Новое время, сопровождающееся на Западе развитием капиталистических отношений и превращением городов в индустриальные центры, в России наступает поздно фактически во второй половине XIX - начале XX в. Однако причина общая - английская промышленная революция 60-х гг. XVIII в., затронувшая не только страны Старого и Нового Света, но и Россию. Расширение географии промышленности способствует возрастанию уровня антропогенного воздействия на природу [12].

Тем не менее, экологические проблемы, возникающие в российских городах на рубеже XIX-XX вв., по мнению исследователей, характерны для Запада XVII-XVIII вв. Загрязнение вызвано не столько промышленными, сколько бытовыми отходами, связано с отсутствием системы их сбора и утилизации, а также ростом концентрации населения. Антисанитарию (отходы и нечистоты) создают преимущественно частные домохозяйства, а наибольший дискомфорт возникает в населенных пунктах, население которых 
превышает 10 тыс. человек [1]. Таким образом, на рубеже веков городские экологические проблемы пока зависят не столько от промышленности, сколько от плотности населения на единицу площади.

Начавшийся промышленный подъем, продемонстрировавший рост городов и городского населения, оказался прерван событиями начала XX в. - прежде всего революцией 1905-1907 гг. и Первой мировой войной. В XX в. Россия вступила, по сути, аграрной страной с традиционным типом общества. После революции 1917 г. за короткий период были реализованы амбициозные планы советской власти, осуществившей индустриализацию и обеспечившей принудительный переход от традиционного к индустриальному типу обществу.

Экологические аспекты советской урбанизации. Исследуя российскую урбанизацию, авторы отмечают общность тенденций, характерных для перехода от традиционного к индустриальному обществу, акцентируя внимание на особенностях, вытекающих из отечественной цивилизационной специфики. Российская урбанизация не ограничена количественными (увеличением численности городов) и даже качественными (развитие экономики города) параметрами. Она включает распространение самого типа городской жизни, связанного с возникновением новых форм расселения и концентрации определенных видов деятельности [17].

По мнению исследователей, в XX в. на специфику российской урбанизации значительное влияние оказал политический фактор - смена власти, детерминировавший переход от монархического к советскому, а затем и к постсоветскому демократическому этапам развития. Принципиальное отличие между периодами определяется ролью государства в этом процессе. Если в монархический период процесс урбанизации носил преимущественно эволюционный характер (возникновение городов и специфика их деятельности обусловлена естественными причинами - исконно сложившимися видами деятельности, связанными с ресурсной базой), то в советский урбанизационный процесс приобретает характер революционный, обусловленный политической необходимос- тью, связанной со скорейшей индустриализацией страны. Государство впервые после петровской эпохи начинает задавать топографию и демографию урбанизации: новые промышленные предприятия все чаще становятся градообразующим фактором, требующим изменения локации производительных сил [21]. В результате возникновение новых городов приобретает искусственный характер, становится итогом государственных решений, размещающих производительные силы там, где этого требует национальная промышленность.

Догоняющий характер советской модернизации, получившей идеологическое обоснование (догнать и перегнать Запад по темпам промышленного роста и объемам производимой продукции), в сочетании с исторически сложившимся обществом мобилизационного типа, а также и авторитаризмом власти придали советской урбанизации дуальность - уникальность и ущербность [17].

Социальное содержание советской урбанизации, так же как и модернизация экономики, было идеологизировано: от вековой аграрной отсталости - к прекрасному индустриальному будущему. Форсирование индустриализации стремительно превращало вчерашних селян в городских жителей, способствовало перемещению и концентрации огромных людских масс в местах возникновения мощных промышленных предприятий. Перекос в сторону развития производственной инфраструктуры в ущерб инвестирования в развитие культурного пространства привел к серьезному дисбалансу в новых промышленных городах: новации, обусловленные лавинообразным ростом городов, пришли в противоречие с традиционализмом - аграрной ментальностью и сельским общинным сознанием подавляющего большинства их населения [17]. Ситуацию усугубляла политика развития городов, в которой финансирование социально значимых сфер осуществлялось по остаточному принципу.

Потребности социалистической экономики в сочетании с идеологизацией сознания советского человека сыграли свою роль: урбанистический пейзаж индустриализируется и отождествляется с социальным прогрессом, природа превращается в объект эксплуатации, а экологические риски игнорируются. 
В условиях наращивания производственных мощностей и объемов производимой продукции не только в довоенный, но и в послевоенный периоды отсутствуют нормативные документы, регламентирующие природопользование. Вопрос о приоритетности развития (индустриализация страны или поддержание стабильного состояния экосистемы) решается однозначно, понятие «экологические требования» отсутствуют, их влияние на социальную жизнь не принимаются в расчет [2]. Народное хозяйство и ВПК страны нуждаются в развитии промышленных зон, а не в сохранении водных ресурсов и создании рекреационных и зеленых зон. Результат - все формы загрязнения окружающей среды: токсичные выбросы в атмосферу, загрязнение промышленными стоками водных артерий, истощение биоресурсов, скопление промышленных отходов в непосредственной близости от мест проживания населения.

Начиная с революционного десятилетия и до конца 60-х гг. XX в. под флагом стремления в кратчайшие сроки построить социалистическое общество, обладающее развитой экономикой, государственная политика ориентирована на откровенную эксплуатацию природы. Ситуация начинает меняться в 70-е гг. Перед научным сообществом власть впервые ставит задачу выработать обоснованные принципы отношения человека и природы, а также создать ресурсосберегающие технологии. Однако наметившиеся позитивные изменения не смогли переломить силу инерционного развития: природоохранная политика была непоследовательной и во многом декларативной, значительность ресурсного потенциала страны рождала иллюзии относительно его неисчерпаемости, отношение к природе как к источнику жизни, характерное для традиционного дореволюционного российского общества, за годы стремительной советской урбанизации/индустриализации оказалось разрушено.

Экологические аспекты постсоветской урбанизации/деурбанизации. Современная Россия сталкивается с комплексом экологических проблем, порожденных предшествующим этапом общественного развития. Рубеж 80-х - 90-х г. XX в. ознаменовался серьезным экономическим спадом, который привел к социально-экономической деструкции, отразившейся в том числе и на характере постсоветской урбанизации. На экологию постсоветских городов негативное воздействие оказали деурбанизация и мегаполизация.

В широком смысле деурбанизация представляет трансформацию городской среды и социальных аспектов жизни горожан [13]. Деурбанизация постсоветского периода связана, прежде всего, с деградацией городского пространства, вызванной процессом деиндустриализации.

В наиболее тяжелом положении оказались т.н. моногорода, возникшие вокруг советских градообразующих предприятий [9]. Часть из них пришла в упадок в связи с банкротством предприятий. Комплекс проблем, прежде всего экономических (отсутствие финансирования) и миграционных (отток трудоспособного населения в экономически активные зоны), привел к возникновению депрессивных территорий, которые перестали отвечать даже минимальным экологическим требованиям [19]. Возникли заброшенные пространства с разрушающейся инфраструктурой (производственной и городской) и негативными следами осуществляемой ранее промышленной деятельности. Градообразующие предприятия, продолжившие работать в условиях отсутствия необходимого уровня финансирования и изношенности основных фондов, поддерживая социально-экономическую сферу моногородов, не имели возможности осуществлять природоохранные мероприятия даже на минимально необходимом уровне.

Профиль деятельности моногородов был различен, включая не только производство промышленной продукции (военной и гражданской), но и добычу полезных ископаемых. Помимо загрязнения почв, водных ресурсов и атмосферы региона, разработка месторождений приводила к необратимому изменению природного ландшафта и повышению радиационного фона. Настоящим бедствием стали так называемые «шахтерские» моногорода, занятые добычей каменного угля. В постсоветский период нерентабельные шахты чаще всего не проходили процедуру консервации или ликвидации с учетом экологических требований, порождая широкий диапазон про- 
блем: подтопление территорий, загрязнение грунтовых вод, выделение метана, а также загрязнение атмосферы соединениями тяжелых металлов [18].

Общей проблемой была утилизация отходов (промышленных и бытовых) [8]. Как результат - наиболее универсальными проявлениями экологической деградации городской и пригородной территорий моногородов становились заброшенные промзоны и несанкционированные свалки.

В настоящее время пришло понимание, что экологической безопасности угрожает не только ускоренная советская урбанизация, но и постсоветская деурбанизация - упадок моногородов, использующих устаревшие энергоемкие и природозатратные технологии и не имеющих финансирования для диверсификации производств [11].

Основной тренд урбанизационного развития - мегаполизация - уже стал глобальной проблемой. С одной стороны, данная тенденция способствует росту не только национальной, но и мировой экономики, с другой - многократно усиливает нагрузку на экосистему [24]. В различных регионах мира мегаполизация проявляет себя по-разному: Запад прошел пик в 70-е гг. XX в., в то время как развивающиеся страны, напротив, демонстрируют устойчивый рост площадей мегаполисов и увеличение численности их населения. При этом количество самих мегаполисов ограничено - основная масса населения сосредоточена в нескольких центрах, крайне неравномерно увеличивая нагрузку на экосистему [7].

Процесс мегаполизации в России связан с рубежом XX - началом XXI вв. Согласно статистическим данным в начале XXI в. доля городского населения составила 73,1 \%, а к середине XXI в., по прогнозам, увеличится до $82,6 \%{ }^{1}$.

Между крупными городами советской эпохи и современными российскими мегаполисами имеется существенное отличие. Если первые развивались согласно плану в качестве промышленных центров социалистичес- кой экономики, имели развитую инфраструктуру, то в развитии вторых больше стихийности и ситуативности. Рыночная экономика стимулирует появление многофункциональных агломераций, которые зависят, прежде всего, от концентрации финансов, во многом определяющих производственный и человеческий потенциал города. Вместе с тем есть черта, роднящая современные российские мегаполисы с аналогичными городскими образованиями развивающихся стран - это столичные города, исторически являющиеся центрами политической власти - Москва и Санкт-Петербург.

Взаимодействие мегаполиса с окружающей средой едино во всем мире: внешнее заимствование ресурсов (водных, энергетических, пищевых), их переработка, связанная с удовлетворением промышленных и бытовых нужд, и закономерное следствие - выброс в атмосферу пыли, газа, аэрозолей, а в водные артерии - различных стоков (промышленных и бытовых). Картину дополняют городские свалки, на которых аккумулируются отходы, загрязняющие все среды $^{2}$.

Показатели загрязнения окружающей среды в российских мегаполисах пока не критичны, но уже достаточно высоки. Их происхождение - совокупность факторов, связанных с увеличением плотности и численности населения, промышленной деятельностью, транспортной нагрузкой. Их следствие - геохимическое загрязнение центральных районов тяжелыми металлами (цинк, свинец, кадмий, медь, никель, хром), затрагивающее почву и растительность [3]; загрязнение атмосферы, обусловленное совокупностью промышленной и транспортной нагрузки (60-70\% от удельного веса газового загрязнения связано с ростом количества автотранспорта) [10]; уничтожение почвенного покрова на городских и прилежащих к городу территориях (под жилыми кварталами, транспортными магистралями, мусорными полигонами) [4]; ощутимый дефицит водных ресурсов (увеличение потребности в воде более чем в 100 раз) [3].

1 World Urbanization Prospects. The 2019 Revision [Electronic resource]. URL: http://esa.un.org/unpd/wup/index. htm (date accessed: 07.08.2021).

2 Развитие современных городов [Электронный ресурс]. URL: https://infopedia.su/13x10b05.html (дата обращения: 22.07.2021). 
Заключение. Экологические аспекты российской урбанизации/деурбанизации отражают как глобальные тенденции развития человечества, так и цивилизационные особенности России.

В целом угрозы экологии городов и прилежащих к ним территорий обусловлены универсальными факторами: интенсификацией урбанизационного процесса; тенденциями мегаполизации; приоритетом экономических интересов над экологической безопасностью; инфраструктурой, чаще всего не отвечающей потребностям мегаполиса; ограниченностью ресурсного потенциала окружающей среды и снижением способности природных комплексов к эффективному самовосстановлению. Ситуацию усугубляет прямо пропорциональная зависимость между величиной городского образования и сложностью экологических проблем.

Российская цивилизационная специфика связана с быстрым разрушением природоориентированного сознания традиционного дореволюционного общества и укоренением идей покорения и эксплуатации природы; с догоняющим характером советской модернизации, потребовавшей за короткий период осуществить урбанизацию/индустриализацию аграрной страны; с дисбалансом между новациями (стремительным ростом городов) и традиционализмом (аграрной ментальностью и общинным типом сознания их населения); с тенденциями деурбанизации, возникшими в постсоветский период и связанными с деиндустриализацией, следствием которой стало появление депрессивных территорий; со значительностью пространств, позволяющих пока не задумываться о последствиях неэффективных программ утилизации промышленных и бытовых отходов.

\section{Список источников}

1. Агафонова А.Б. Экологические проблемы городской среды в XIX - начале XX веков // Вестник Череповецкого государственного университета. 2014. №7. С. 28-32.

2. Бельков А.В., Козырева М.В., Тарасенко А.А. Влияние аксиосферы культуры и правоприменения на формирование эколого-экономического мышления в промышленно развитых регионах // Экологические проблемы промышленно развитых и ресурсодобывающих регионов и пути решения. Кемерово, 2017. С. 202-204.

3. Блинов Л.Н., Перфилова И.Л., Юмашева Л.В., Соколова Т. В. Экологические проблемы мегаполисов // Здоровье - основа человеческого потенциала: проблемы и пути их решения. 2013. Т. 8. №2. С. 837-845.

4. Боднарук М.Н., Попов С.М., Козлов О.В. Современные проблемы обращения городских отходов в природопользовании // Горный информационно аналитический бюллетень (научно-технический журнал). 2012. №4-10. С. 3-8.

5. Бродель Ф. О своеобразии городов Запада // Материальная цивилизация, экономика и капитализм XV-XVIII вв. T. 1. Структуры повседневности: Возможное и невозможное. М.: Весь мир, 2007. 592 с. $252 \mathrm{c}$.

6. Вебер М. Город. М.: Strelka Press, 2017.

7. Галич 3.Н. Урбанизация и мегаполизация как глобальный процесс // Экономические и социальные проблемы России. 2000. №1. C. 7-21.

8. Гундарев А.А. Системный подход в исследовании моногородов // Архитектура, градостроительство и дизайн. 2015. №7. С. 18-24.

9. Дмитриева Е.О., Мост Е.С. Экологические проблемы устойчивого развития моногорода Чапаевск и пути их решения на современном этапе // Вестник Евразийской науки. 2018. №6. С. 157-165.

10. Зеркалов Д.В. Экологическая безопасность. Киев: Основа, 2012. 506 с.

11. Зиновьева Е.Г., Захарова Я.М., Степашков П.Ю. Экологические проблемы монопрофильных городов и пути их решения// Российские регионы в фокусе перемен. Екатеринбург: Изд-во УМЦ УПИ, 2020. С. 627-630.

12. Калимуллин А. М. Историко-экологический подход в изучении истории города // Вестник ТГГПУ. 2010. №3(21). С. 122-126.

13. Киреева О.В. Урбанизация и дезурбанизация в истории русской культуры // Парадигма: философско-культурологический альманах. 2020. №32. С. 80-95.

14. Ле Гофф Ж. Цивилизация средневекового Запада. М.: Издательская группа Прогресс, Прогресс-Академия, 1992. 376 с.

15. Лефевр А. Производство пространства. М.: Strelka Press, 2015. 432 c. 
16. Монтескье Ш. Избранные произведения. М.: Политиздат, 1955. 803 с.

17. Пивоваров Ю.Л. Урбанизация в России в XX веке: представление и реальность // Общественные науки и современность. 2001. №6. C. 101-113.

18. Приваленко В. В., Кузина 3. Р., Коломенский Г.Ю., Гипич Л.В. Экологические проблемы Восточного Донбасса // Известия вузов. Северо-Кавказский регион. Естественные науки. 2004. №7. С. 36-49.

19. Родяшина К.Е. Депрессивные территории в структуре современного города: понятия, характеристики, классификация // Вестник БГТУ им. В.Г. Шухова. 2017. №8. С. 106-114.

20. Руссо Ж.-Ж. Трактаты. М.: Книга по Требованию, 2012. 710 с.

21. Сенявский А.С. Российская урбанизация: некоторые историко-методологические проблемы // Урбанизация в формировании социокультурного пространства. М.: Наука, 1999. С. 153-164.

22. Тетиор А.Н. Тенденции урбанизации Земли // Евразийский Союз Ученых (ЕСУ). 2015. №9 (18). C. 11-15.

23. Castells M. The Power of Identity. Vol.2// The Information Age: Economy, Society and Culture. Oxford and Malden, Mass: Blackwell Publishers, 1997. 337 p.

24. Pommellet P. Les grandes metropoles // Etudes. 1989. Vol. 379. №2.

\section{References}

1. Agafonova A.B. Jekologicheskie problemy gorodskoj sredy v XIX — nachale XX vekov [Ecological problems of the urban environment in the XIX - early XX centuries]. Vestnik Cherepoveckogo gosudarstvennogo universiteta [Bulletin of the Cherepovets State University]. 2014; (7): 28-32. (In Russ.).

2. Bel'kov A. V., Kozyreva M.V., Tarasenko A.A. Vlijanie aksiosfery kul'tury i pravoprimenenija na formirovanie jekologo-jekonomicheskogo myshlenija $\mathrm{v}$ promyshlenno razvityh regionah [Influence of the axiosphere of culture and law enforcement on the formation of ecological and economic thinking in industrially developed regions]. Jekologicheskie problemy promyshlenno razvityh i resursodobyvajushhih regionov i puti reshenija [Ecological problems of industrially developed and resource-extracting regions and solutions]. Kemerovo, 2017. P.202204. (In Russ.).

3. Blinov L.N., Perfilova I.L., Jumasheva L.V., Sokolova T. V. Jekologicheskie problemy megapolisov [Ecological problems of megacities]. Zdorov'e - osnova chelovecheskogo potenciala: problemy i puti ih reshenija [Health is the basis of human potential: problems and solutions]. 2013; 8(2): 837-845. (In Russ.).

4. Bodnaruk M.N.,Popov S. M., Kozlov O. V. Sovremennye problemy obrashhenija gorodskih othodov v prirodopol'zovanii [Modern problems of urban waste management in environmental management]. Gornyj informacionno analiticheskij bjulleten' (nauchno-tehnicheskij zhurnal) [Mining information and analytical bulletin (scientific and technical journal)]. 2012; (4-10): 3-8. (In Russ.).

5. Brodel' F. O svoeobrazii gorodov Zapada [About the originality of the cities of the West]. Material'naja civilizacija, jekonomika i kapitalizm XV-XVIII vv. T. 1. Struktury povsednevnosti: Vozmozhnoe i nevozmozhnoe [Material civilization, economics and capitalism of the 15th-18th centuries. Vol. 1. The structures of everyday life: Possible and impossible]. Moscow: Ves' mir, 2007. 592 p. (In Russ.).

6. Veber M. Gorod [City]. Moscow: Strelka Press, 2017. 252 p. (In Russ.).

7. Galich Z.N. Urbanizacija i megapolizacija kak global'nyj process [Urbanization and megapolization as a global process]. Jekonomicheskie i social'nye problemy Rossii [Economic and social problems of Russia]. 2000; (1): 7-21. (In Russ.).

8. Gundarev A.A. Sistemnyj podhod v issledovanii monogorodov [A systematic approach in the study of single-industry towns]. Arhitektura, gradostroitel'stvo $i$ dizajn [Architecture, urban planning and design]. 2015; (7): 18-24. (In Russ.).

9. Dmitrieva E. O., Most E. S. Jekologicheskie problemy ustojchivogo razvitija monogoroda Chapaevsk i puti ih reshenija na sovremennom jetape [Ecological problems of sustainable development of the monotown Chapaevsk and ways to solve them at the present stage]. Vestnik Evrazijskoj nauki [Bulletin of Eurasian Science]. 2018; (6): 157-165. (In Russ.).

10. Zerkalov D. V. Jekologicheskaja bezopasnost' [Environmental safety]. Kiev: Osnova, 2012. 506 p. (In Russ.). 
11. Zinov'eva E. G., Zaharova Ja. M., Stepashkov P. Ju. Jekologicheskie problemy monoprofil'nyh gorodov i puti ih reshenija [Ecological problems of single-industry cities and ways of their solution]. Rossijskie regiony $\mathrm{V}$ fokuse peremen [Russian regions in the focus of changes]. Ekaterinburg: Izd-vo UMC UPI, 2020. P. 627-630. (In Russ.).

12. Kalimullin A. M. Istoriko-jekologicheskij podhod $\mathrm{v}$ izuchenii istorii goroda [Historical and ecological approach in the study of the history of the city]. Vestnik TGGPU [Bulletin of the TGGPU]. 2010; 3(21): 122-126. (In Russ.).

13. Kireeva O.V. Urbanizacija i dezurbanizacija $\mathrm{v}$ istorii russkoj kul'tury [Urbanization and deurbanization in the history of Russian culture] // Paradigma: filosofsko-kul turologicheskij al'manah [Paradigm: philosophical and cultural almanac]. 2020; (32): 80-95. (In Russ.).

14. Le Goff Zh. Civilizacija srednevekovogo Zapada [Civilization of the Medieval West]. Moscow: Izdatel'skaja gruppa Progress, Progress-Akademija, 1992. 376 p. (In Russ.).

15. Lefevr A. Proizvodstvo prostranstva [Production of space]. Moscow: Strelka Press, 2015. 432 p. (In Russ.).

16. Montesk'e Sh. Izbrannye proizvedenija [Selected works]. Moscow: Politizdat, 1955. 803 p. (In Russ.).

17. Pivovarov Ju. L. Urbanizacija v Rossii v XX veke: predstavlenie i real'nost' [Urbanization in Russia in the XX century: representation and reality]. Obshhestvennye nauki i sovremennost' [Social sciences and modernity]. 2001; (6): 101-113. (In Russ.).
18. Privalenko V.V., Kuzina Z. R., Kolomenskij G. Ju., Gipich L. V. Jekologicheskie problemy Vostochnogo Donbassa [Ecological problems of Eastern Donbass]. Izvestija vuzov. Severo-Kavkazskij region. Estestvennye nauki [News of higher educational institutions. North Caucasian region. Natural Sciences]. 2004; (7): 36-49. (In Russ.).

19. Rodjashina K. E. Depressivnye territorii V strukture sovremennogo goroda: ponjatija, harakteristiki, klassifikacija [Depressive territories in the structure of a modern city: concepts, characteristics, classification]. Vestnik BGTU im. V.G. Shuhova [Bulletin of BSTU named after V.G. Shukhov]. 2017; (8): 106-114. (In Russ.).

20. Russo Zh.-Zh. Traktaty [Treatises]. Moscow: Kniga po Trebovaniju, 2012. 710 p. (In Russ.).

21. Senjavskij A.S. Rossijskaja urbanizacija: nekotorye istoriko-metodologicheskie problemy [Russian urbanization: some historical and methodological problems]. Urbanizacija $\mathrm{v}$ formirovanii sociokul'turnogo prostranstva [Urbanization in the formation of socio-cultural space]. Moscow: Nauka, 1999. P. 153-164. (In Russ.).

22. Tetior A. N. Tendencii urbanizacii Zemli [Trends of urbanization of the Earth]. Evrazijskij Sojuz Uchenyh (ESU) [Eurasian Union of Scientists (ESU)]. 2015; 9(18): 11-15. (In Russ.).

23. Castells M. The Power of Identity. Vol.2// The Information Age: Economy, Society and Culture. Oxford and Malden, Mass: Blackwell Publishers, 1997. 337 p.

24. Pommellet P. Les grandes metropoles // Etudes. 1989. Vol. 379. №2.

Статья поступила в редакиию 28.11.2021; одобрена после рецензирования 02.12.2021; принята к публикации 08.12.2021.

The article was submitted on 28.11.2021; approved after reviewing on 02.12.2021; accepted for publication on 08.12.2021. 


\section{ИНФОРМАЦИЯ ОБ АВТОРАХ}

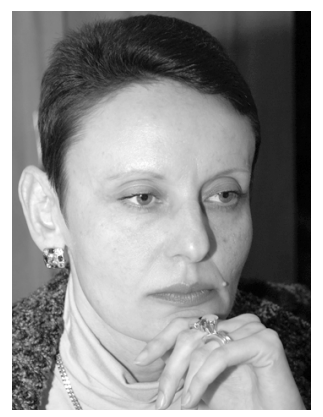

Штофер Людмила Львовна - кандидат философских наук, доцент, доцент кафедры «Философия и культурология», Ростовский государственный экономический университет (РИНХ). Специалист в области исследования геополитических процессов, военной, экономической и информационной безопасности, духовного отчуждения, экологической культуры. Стаж научной работы - 23 года.

Россия, г. Ростов-на-Дону, ул. Большая Садовая, 69

Lyudmila L. Shtofer - Candidate of Philosophical Sciences, Associate Professor, Associate Professor of the Department of Philosophy and Culturology, Rostov State Economic University (RINH). Specialist in the field of research of geopolitical processes, military and information security, spiritual alienation, ecological culture. Scientific work experience is 23 years.

69 Bolshaya Sadovaya st., Rostov-on-Don, Russia

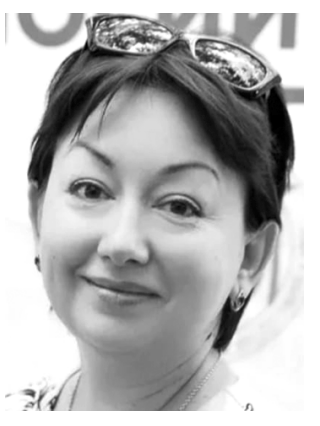

Шевченко Ольга Михайловна - доктор философских наук, доцент, профессор кафедры «Конфликтология и национальная безопасность», Институт социологии и регионоведения, Южный федеральный университет. Специалист в области исследования этнополитических процессов, межэтнических отношений, национальной и духовной безопасности общества, культуры гражданственности. Стаж научной работы - 25 лет.

Россия, г. Ростов-на-Дону, ул. Пушкинская, 160

Olga M. Shevchenko - Doctor of Philosophical Sciences, Associate Professor, Professor of the Department of Conflictology and National Security, Institute of Sociology and Regional Studies, Southern Federal University. A specialist in the field of research on ethnopolitical processes, interethnic relations, national and spiritual security of society, civil practices. Scientific work experience is 25 years.

160 Pushkinskaya st., Rostov-on-Don, Russia

\section{Вклад авторов:}

Штофер Л.Л. - научное руководство; концепция исследования; доработка текста; итоговые выводы.

Шевченко О.М. - развитие методологии; написание исходного текста; итоговые выводbl.

Contribution of the authors:

Shtofer L.L. - scientific management; research concept; writing the source text4 final conclusions.

Shevchenko O. M. — development of methodology; follow-on version of the text; final conclusions. 